been obtained with dichlor-diphenyl-trichlorethane (D.D.T.) as an insecticide, and the compound seems to merit field trial as a substitute for lead arsenate. Records of mineral-deficiency responses in plants have been extended, and symptoms for twenty-three new crops added to the list. As regards advisory work, a total of 10,880 letters were dispatched and forty-three papers published in scientific journals by members of the Long Ashton, Berkeley Square and Campden staffs.

\section{Indian Woods for Textile and Jute Mill Accessories}

IN Indian Forest Bulletins Nos. 121 and 122 (1943) (Forest Research Laboratory, Dehra Dun) substitutes are proposed for imported cotton mill shuttles, bobbins, etc. In Bulletin No. 121, by M. A. Rehman, the results of tests carried out at the Research Institute, Dehra Dun, on the suitability of Indian timbers for cotton mill shuttles for power looms, to replace cornel and persimmon ones imported from America, are described. A large number of timbers considered suitable for their known characteristics were tested. After elimination, the seasoned and selected blanks of woods which appeared promising were sent out for manufacturing trials. The finished shuttles were then tested in weaving mills under factory conditions. Results have shown that the light-coloured sapwood of Diospyros melanoxylon or ebony is the best Indian timber so far tested for shuttles. It gives about 50 per cent of the life of imported timber. Other species mentioned in the Bulletin are being used in parts of India where the particular timbers are more easily obtainable.

Bulletin No. 122, by M. A. Rehman and Chheda Lal, treats of the care and seasoning of woods for bobbins, picker arms and jute mill rollers. Suggestions are made for using indigenous woods for the manufacture of these implements; for example, imported bobbins were of beech, birch and maple. Sixteen Indian species of woods belonging to fifteen genera growing in different provinces have been tried out. Species of four of these genera are used extensively throughout the country for bobbin-making. Their life does not appear to be much more than 30 per cent of the imported bobbins. Picker arms and jute mill rollers are also discussed.

\section{Forests of Trinidad}

THE present position of forestry in Trinidad (Trinidad and Tobago, Forest Dept. Admin. Report for Year 1943. Trinidad and Tobago : Govt. Printer) appears to be of considerable interest. There are not many British Colonies which can state that the general position with regard to forest reservation is eminently satisfactory, and that the forest reserves occupy $22 \cdot 7$ of the total area of the Colony "after deducting the area leased to the U.S.A."; and further, that "almost all the forest reserves are now governed by Working Plans under which some form of elementary yield control has been introduced". This is, or should be, the first object in management to be aimed at by the trained forest officer; but, whatever the reasons, it has been neglected in most of the forest regions under the Colonial Office. As elsewhere in the British Empire, the bar-restrictions in timber imports have resulted in the demand for unseasoned local timber exceeding the supply. This being the case, it is difficult to follow the argument that high costs (these prevail everywhere), low volume production per acre (common to the tropical mixed forest generally), and high loss in conversion of tropical woods make it doubtful whether any such supply from the natural mixed forests could in normal times compete with imports. The exploitation of the more or less gregarious Mora forests has been under consideration for years; it is now said that there is a high conversion loss owing to the refractory nature of Mora as a timber. It would appear that there is now an unexpected chance to introduce, as has always been the case in most parts of India, the indigenous Trinidad timbers to the population in such a manner as to render their use a permanency in the Colony. There is no mention in the report of a recognition of the advantages offered to the type of forests existing in Trinidad by the introduction of a plywood mill.

\section{British Astronomical Association}

A BROCHURE entitled "The British Astronomical Association. Its Nature, Aims and Methods" has been issued by the Association with the main object of encouraging amateurs to undertake astronomical work. Fourteen sections are now in existence, and valuable work is still being done in spite of the difficulties of war conditions. Novices need not be deterred even if they have very little instrumental equipment; in some cases, such as the observation of meteors, auroras, zodiacal light and in historical research, etc., no equipment of any kind is necessary. Proof of the important work that amateurs can do is afforded by a recent triumph of the Computing Section under Mr. J. G. Porter ; with the help of four members of this Section, a definitive orbit of Comet PonsWinnecke has just been computed (J. Brit. Astro. Assoc., 54, 7 ; 1944). This is probably the first time in the history of astronomy that a body of amateurs has computed a definitive orbit, and it is a testimony to their wonderful patience and skill in handling figures that this formidable work has been accomplished.

Fifty-four years of work by members of the Association have seen much accomplished and also an increasing interest in astronomy. The membership has had a remarkable growth within the last few years and now exceeds 1,200. During the War, the Association moved its meeting place and library to the premises of the Royal Astronomical Society, Burlington House, Piccadilly. Information regarding conditions of membership, etc., should be addressed to the secretary at the above address. Mr. F. J. Hargreaves retired from the presidency in October and the new president is Mr. P. J. Melotte, of the Royal Observatory, Greenwich.

\section{Public Health in Turkey}

ThE Asiatic Review of October contains an interesting article by Bay Nuzhet Baba on the public health effort and social assistance in Turkey. The central authority in charge of health and social assistance is the Ministry of Health and Social Assistance. Free treatment of the sick, campaigns against epidemics and diseases, especially malaria, trachoma, typhoid fever and dysentery, all fall within the sphere of activity of the Ministry. To the Ministry also are entrusted the supervision of maternity homes, hospitals and sanatoria. In order to emphasize the importance of medical examination of school children, dental care, vaccination against small-pox, inoculations, etc., the Ministry has drawn up regulations whereby municipalities are obliged to provide such 